\title{
Research on the Transformation of Traditional Enterprise Management Model in Big Data Era
}

\author{
Duan Yasha \\ Taiyuan City Vocational College, Taiyuan, China, 030031
}

Keywords: big data; business operations; enterprise management; management innovation

\begin{abstract}
At present, the economic development of countries is relatively rapid. Various data play a very important role in the daily operation of the company. The rapid development of the economy has brought us into the era of big data. The arrival of the era of big data has brought tremendous impact to the operation of traditional business models. A large amount of data makes traditional data collection methods not enough for the current needs of enterprises, and a large amount of data is more efficient and reasonable. This paper first introduces the background of big data, gives the related concepts of big data, and combines the characteristics of current enterprises in China, and focuses on the enterprise management innovation model based on big data, and explores the transformation mode of enterprise management.
\end{abstract}

\section{Introduction}

In recent years, computer and information technology have developed rapidly, leading to the emergence of big data in various fields. The continuous generation and collection of various data sources has led to the emergence of "massive data". Due to the rapid development and popularization of the Internet, people's lifestyles are gradually affected by big data, which will surely bring about changes in people's thinking patterns, and promote social progress and development. The big data logo is not to master the data, to obtain massive data, to analyze and study the data, to make statistical predictions on the probability of occurrence of relevant events based on the results of the data analysis, and to make scientific and reasonable decisions based on these prediction data to avoid causing no The necessary loss. The traditional enterprise management model has been unable to adapt in the era of big data, reducing the competitiveness of enterprises in the new situation. Failure to analyze useful information based on customer spending records and related information will result in the elimination of new competition. As the social development gradually enters the era of big data, this development trend and environment, there are various challenges for enterprises, and more development opportunities. Therefore, with big data as the background of the times, research on corporate management is even more important[1].

\section{Meaning of big data}

The early definition of "big data" was given by McKinsey Information Consulting, Inc., specifically: "Data has become an important production factor in all walks of life." "Big Data" is defined in Wikipedia as: "The collection of data that is crawled, managed, and processed by content using a regular software tool within an allowed timeframe is big data." This paper argues that the so-called "big data" refers to the traditional database software processing capabilities and the vast amount of data that information technology cannot handle. According to relevant statistics, the scale of China's big data technology and service market has increased from 77.6 million US dollars in 2011 to 617 million US dollars in 2016, with a growth rate of 795\%. In the next five years, the compound growth rate will also maintain rapid growth, with a forecast of $51.4 \%$, and the market size is also growing at a large rate, which is expected to expand sevenfold. However, many companies in China have not yet fully adapted to the impact of "big data" and face many challenges. 


\section{Comparison of Enterprise Management Model Innovation under the Background of Traditional Model and Big Data}

The traditional model refers to the exploratory innovation driven by the problem and the specific enterprise management problem. The professional knowledge, the humanized management and the system management are taken as the starting point, and the quantitative analysis and the qualitative analysis are combined to solve the problem solving method. To achieve innovation in the field of business management. In the context of the era of big data, the innovation environment and innovation conditions of enterprises are more complex, and they are full of uncertainties and uncertain factors. Enterprises also have more possible innovation choices, and there will be more innovative methods of enterprise management. The traditional enterprise management model is like "pond fishing"; in the context of big data, the enterprise management innovation model is like "sea fishing", with more uncertainty, and the "fish" for alternatives. . Due to changes in the external environment of enterprises, enterprise management innovation in the big data environment is fundamentally different from traditional enterprise management[2].The development trend of big data application is as follows.

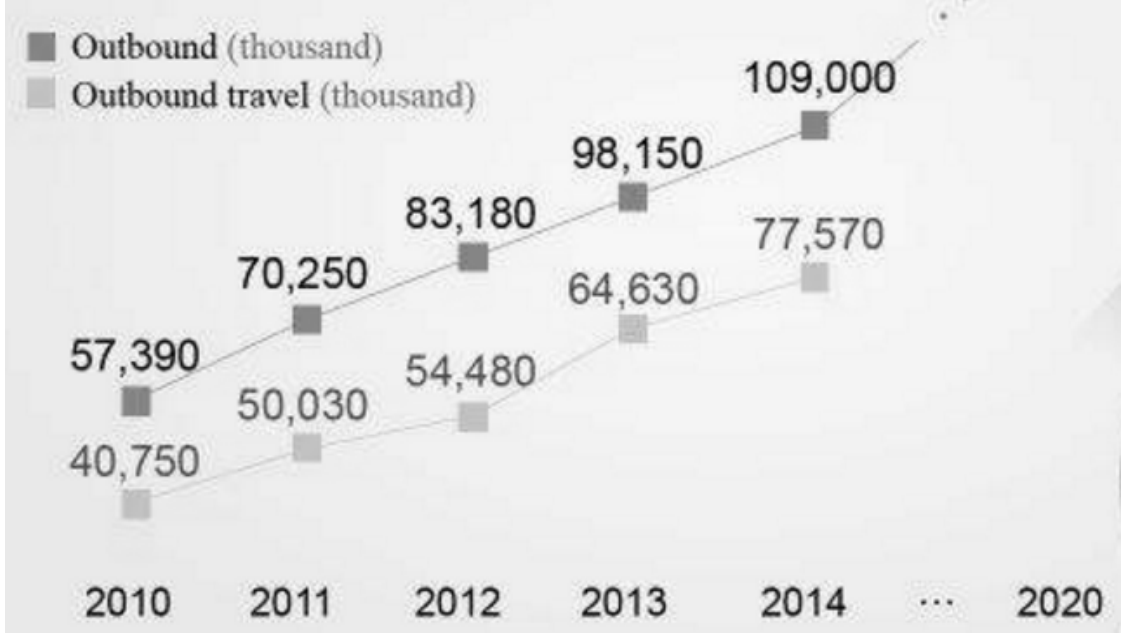

Fig.1 Development trend of big data application

\section{Enterprise Management Model Innovation under the Background of Big Data}

\subsection{Acquisition of data and data platform formation}

In the context of the era of big data, enterprise data platforms play an important role in the innovation management of data or problem-driven enterprises, and play the role of data monitoring, collection, analysis, processing and storage in business operations[3].

\subsection{Enterprise Innovation Issues and Program Decisions}

In the business activities, once problems are discovered, it is first necessary to determine whether it is necessary to innovate enterprise management. Obtaining and collecting relevant data is a factor related to decision-making. Data can be collected using computer information technology. Whether innovation and innovation can be successful, decisions must be made based on the data collected. To carry out management innovation, the first thing to do is to define the innovation problem: to identify the areas and scopes that need to be innovated; to elaborate on the innovation issues through the preliminary analysis of the data. Based on the definition of innovation problems, use various data analysis techniques to mine hidden deep information in the data. According to the results of the data analysis, the feasibility of the proposed alternatives is analyzed and verified, and the most credible scheme is selected. Enterprise management mode as shown below. 


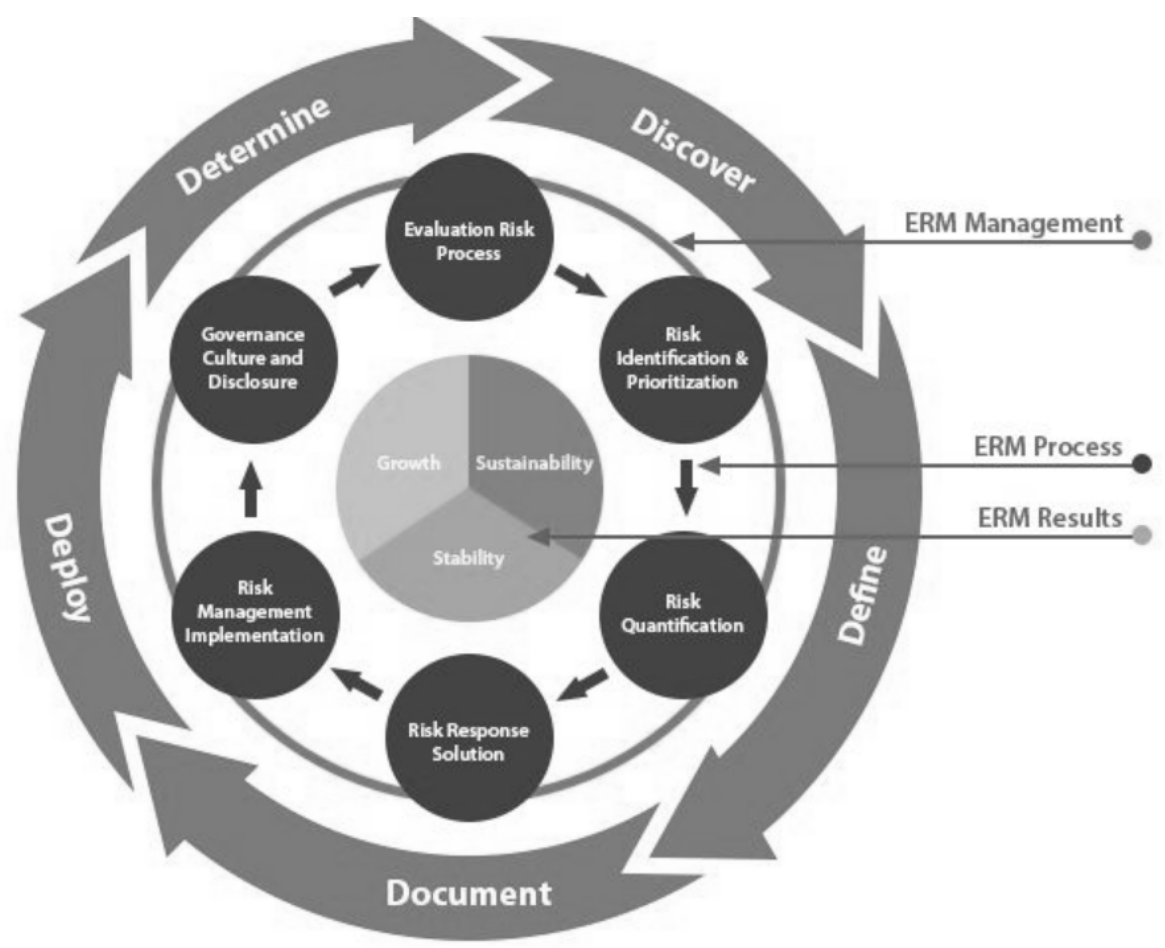

Fig.2 Enterprise management mode

\subsection{Dynamic data and implementation of innovative solutions}

The process of implementing the innovative plan is also the process of continuously accumulating performance data and implementing data. Collecting, analyzing and sorting these real-time data, adding it to the data sharing platform data source, analyzing and feedbackting these real-time data, and the enterprise in the innovative program Real-time correction of deviations during implementation, real-time monitoring and optimization of innovative solutions to ensure the successful completion of innovation goals. In order to ensure the implementation process of the innovative solution, it is a process of real-time feedback and continuous improvement, thereby increasing the probability of success of the enterprise innovation program[4].In today's society, many new media platforms are extremely active, providing more choices for data processing and analysis. For example, new media can be used to put documents, data, and other information into an unstructured analytical framework, dealing with emotions, structures, and even words and phrases to understand the visibility, credibility, and product of the company in the market. Quality, deficiencies, etc., in order to provide a data basis for more accurate market decisions. At the same time, it is also possible to combine new technologies with traditional data processing methods, so that customers can understand the business philosophy and business model of the company more comprehensively and comprehensively on the basis of understanding the traditional enterprise information, so as to communicate with customers at the fastest speed. Market, identify the market positioning. It can also enhance the status image of the company in the eyes of customers and lay a foundation for the long-term development of the company.

\subsection{Data Utilization and Enhancement of Innovation}

In the context of the era of big data, in the implementation process of innovative solutions, data analysis results have been verified in real time, and corresponding corrections and adjustments are made according to the internal and external environment faced by enterprises to ensure the smooth progress of innovative solutions; The internal and external environment of the enterprise is different, avoiding the introduction of other similar innovative solutions; in the process of implementing the innovative solutions of the enterprise, collecting data in real time, analyzing the data, according to the analysis As a result, the original management plan was revised to achieve the effect of improving the innovative program. 


\section{Summary}

This paper first introduces the background of big data, gives the related concepts of big data, analyzes the differences between traditional enterprises and enterprise management models in the era of big data, and analyzes the problems that enterprises should face in the context of big data. The most important of these is the change in the mindset of business managers. Most of the enterprise managers have not realized the crisis faced by enterprises under the background of big data, and do not pay much attention to the use of big data. This paper discusses several innovative models of enterprise management in the era of big data, and provides reference for enterprise development and management.

\section{References}

[1] He Jiang, Wei Xiong, Yonghui Cao. A Conceptual Model of Excellent Performance Mode of Port Enterprise Logistics Management[J]. Polish Maritime Research,2017,24(s1).

[2] Ercan Oztemel, Seher Arslankaya, Tulay Korkusuz Polat. Enterprise knowledge management model (EKMM) in strategic enterprise resource management (SERM)[J]. Procedia - Social and Behavioral Sciences,2011,24.

[3] Fábio Lotti Oliva. A maturity model for enterprise risk management[J]. International Journal of Production Economics,2016,173.

[4] Zhijun CHEN. Construction of the Capability Maturity Model of Dynamic Strategic Cost Management on Real Estate Development Enterprises[J]. Canadian Social Science,2015,11(11). 